\title{
Stellenbosch coffee society: Societal and locational preferences
}

\begin{abstract}
Stellenbosch is a university town boasting knowledge-intensive economic sectors with a variety of "new economy' occupations and activities. The presence of a professional and creative class, as well as university students has changed the economy, the retail landscape and the social spaces of the town. This paper reports on an investigation of the geography of coffee shops (third places) in downtown Stellenbosch and describes the social and physical factors which influence customer preferences for certain coffee shops. A brief review of the literature on the evolution of coffee shop and café cultures, the functioning as third places and the siting of coffee shops in inner cities (or specific neighbourhoods) is presented. A mixed-methods research approach consisting of transect walks, a questionnaire survey and three in-depth-interviews with coffee shop owners (or managers) is explained. The study area in the historical precinct of the town is contextualised. The bigger picture of coffee consumption in Stellenbosch - social and locational preferences, place attachments of consumers and the relative location of coffee shops - is sketched. The findings of three in-depth case studies (selected speciality coffee shops) are discussed. The paper concludes by pointing out some implications for the planning of consumption spaces in secondary cities in developing world contexts.
\end{abstract}

Keywords: coffee shops, third places, new economy, locational preferences, place attachment

\section{Introduction}

Visiting coffee shops is now commonplace and this phenomenon has resulted in an urban geography of consumption spaces. Ever since the early eighteenth century, social gathering places - the so-called third places - gained importance in cities. Coffee shops are often prevalent in these spaces (Oldenburg, 1999; Trugman, 2016). These familiar coffee shops in certain urban neighbourhoods are daily rituals and influence the routines of people (Waxman, 2006). Customers frequent coffee shops for many more reasons than just sating hunger or quenching thirst. There is the escape from a stressful office, the chance to maintain or grow a relationship, a place to get away for some reflective work, a chance to engage with friendly coffee shop staff at a particularly lonely time or as a place to do business and reach agreements (Baskerville, 2015). Coffee shops are a singularly important feature of a vast network of gathering spaces that make up our urban areas (Topik 2009). A coffee shop is a place where coffee is only a pretext to obtain other experiences. Patrons know "that there is more than coffee, eating and drinking in coffee shops: different kinds of sense, feeling, experience, culture and globalisation" (Sohrabi, 2016: 1). For long coffee shops have been places of social interaction and given that coffee is the most widely consumed beverage in the world $^{1}$, it is vital to understand the geography of these spaces of consumption (Oldenburg, 1999; Elliott, 2001; Cowan, 2005; Topik, 2009; Trugman, 2016).

Stellenbosch is a University town that prides itself with knowledge-intensive economic sectors and a variety of 'new economy' occupations and activities. The presence of a professional and creative class, as well as students, has changed the economy, the retail

\footnotetext{
${ }^{1}$ Large transnational companies like Starbucks are amplifying the spread of a coffee culture.
} 
landscape and the social spaces of the town. Stellenbosch is the location of head offices of prominent private investment, auditing and legal companies and a popular tourist- and leisure destination. Although Stellenbosch is well known for its quality wines, it also enjoys a thriving coffee consumption culture. In this research, a coffee shop is defined as a public gathering place, privately owned and locally managed, where coffee is served from a wide list of coffee blends as part of the establishment's food and beverage list. A specialised coffee shop - is a coffee shop where coffee sales make up at least $60 \%$ of the establishment's revenue and where "specialty coffees" are available. Coffee are marketed as organic coffees, Fair Trade coffees, and other seemingly socially responsible coffees (West, 2010; Tumanan \& Lansangan, 2012). This investigation aims to shed light on the local coffee culture and to capture the social and physical factors that influence the consumer preferences for certain coffee shops. To understand the siting of the town's coffee shops, who they cater for and the reasons for their success, the opinions of the owners (or managers) of three speciality coffee shops were investigated. The paper has six-sections of review and analysis. First, a brief review of the literature on the evolution of coffee shop and café cultures, the functioning as third places and the locations of coffee shops in certain urban precincts is presented. Second, a mix-methods research approach consisting of transect walks, a questionnaire survey and three in-depth interviews with the owners or managers of speciality coffee shops is explained. Third, the study area in historic central Stellenbosch is contextualised. Fourth, the bigger picture of coffee consumption in Stellenbosch downtown - the social and locational preferences, place attachments of consumers and the relative location of coffee shops - is sketched. Fifth, the findings of three case studies of selected speciality coffee shops are discussed and conclusions are drawn. Last, recommendations are made to the local municipality regarding the licensing of new coffee shops and the siting of these new shops.

\section{Coffee shops: Origins, social functions, physical factors and locations}

There has been a variety of studies on the social nature of cafés and coffee shops over the past decades (Tjora, 2013). These include amongst others: coffee shops and political culture (Pincus, 1995); café culture (Montgomery, 1997); coffee shops as third places (Oldenburg, 1999); coffee shops and reduced levels of crime (Papachristos et al., 2011); coffee culture (Tucker, 2017); coffee shops and social movements (Sohrabi, 2016); and cappuccino cities (Austin \& Whitehead, 1998; Laurier \& Philo 2005; Hyra, 2017). This paper concentrates on the origins of coffee shops and café culture in urban spaces, coffee shops as third places and the geography of coffee shops.

\subsection{Origins of coffee shops and café culture}

The drinking of coffee in the world has been an integral part of social life for a long time. In the early 1500s, there were already coffee shops established in Cairo and Damascus (Kafadar, 2014). By the end of the sixteenth century, there were hundreds of coffeehouses in Istanbul and many more hundreds spread across the Ottoman Empire (Örs, 2002). The emergence and spread of coffeehouses in Istanbul coincided with various other dynamics and processes of the early modern era (changing night-time practices, including the emergence of certain new forms of art and public entertainment) (Kafadar, 2014). The first coffeehouse in the United Kingdom was established in Oxford (university town) in 1650. While the first coffeehouse in London opened its doors to the public in 1652. By the first decade of the eighteenth century, London had 3,000 coffeehouses, each with a core group of regulars (Lillywhite, 1963). Coffeehouses were the "prime information centres ... at this time. It was here that the 
newspapers were read, that tracts and leaflets were published, that insurance was invented, that all manner of business was transacted" (Sennett, 1974: 82). Since the 1950s coffee has become a favourite drink in most western societies with countless North Americans consuming coffee daily (Elliott, 2001). Coffee shops and the popularity of consuming coffee have come a long way since the early work of Harbermas ${ }^{2}$ (1989) which described 'English coffeehouses' as contained and egalitarian spaces for calm, rational-critical debates. The historical role of coffee shops has been one of venues for social intercourse, conversation and political debate.

To improve and re-create the urban public realm - a number of UK cities have tried to create a certain level of café culture - as part of a wider drive to earmark investment for the redesign of plazas, streets and parks (Landry \& Bianchini, 1995; Lovatt \& O'Connor, 1995; Kjeldgaard \& Ostberg, 2007). These designs were intended to encourage a more active social life in urban public space (Montgomery, 1997). In Utrecht, Oosterman (1992: 161) has argued that the "sidewalk café is an excellent example of ... individual pleasure derived from the public realm". The entertaining force of the street is the main attraction of the sidewalk café (Oosterman, 1992: 161). Oosterman's (1992) research has revealed that the 'best' cafés were those where the street life around them is heterogeneous, but that each café can be distinguished by special characteristics such as the age and consumption patterns and lifestyles of its clientele. Within countries, some cities have more vibrant public social lives than others do. This means that the "cultural influences on public social life exist at the 'macro' level - but they are also partly a reflection of micro-conditions, customs and traditions" (Montgomery, 1997: 89). Coffeehouses in Austria are something of an institution and act as traditional meeting places. A café (Ger. Kaffeehaus) is the best place to relax, read the newspaper and to enjoy the good things in life. In Vienna - a city ranked with the highest quality of life for the ninth year in a row (Shea, 2018) - the drinking of coffee is a way of life, and a distinct and essential part of local culture. UNESCO added Viennese coffee house culture to their list of intangible cultural heritage, saying that the coffeehouses have a 'very specific atmosphere' and are places where coffee, time and space are consumed (Hoeller, 2015). Concomitant with urbanisation processes, the coffee shop today epitomises a society with less time for long lunches, on the lookout for a place to socialise, multitask, catch up on work or do other related tasks (Elliott, 2001).

\subsection{Coffee shops as third places}

Ray Oldenburg (1999) coined the term 'third place' in his book 'The Great Good Place'. Cafés are quintessential third places, 'homes away from home', where unrelated people relate. These local, accessible and inclusive 'great, good places' act as staging grounds for cultivating the vital informal public life fundamental to all cultures. Third places are characteristically places that help people get through the day and they differ from the usual gathering places such as home or work in our modern societies. They are social gathering places serving as a middle ground, as a third place between home and work. Third places are those public places that "host the regular, voluntary, informal, and happily anticipated gatherings of individuals" (Oldenburg, 1999: 16). Coffee shops had become places where people would gather, speak freely and mingle with others from their community, disregarding rank and social status (Sennet, 1974; Oldenburg, 1999; Pendergrast, 1999). These third places act as conductors in society, providing neutral ground where one is easily able to connect

\footnotetext{
${ }^{2}$ Harbermas' 1962 book on English coffee houses was originally published in German and translated into English in 1989.
} 
with people as well as exchange news and ideas (Waxman, 2006). Third places have been integral in facilitating communication while their "significance has increased during specific historic periods, providing a petri dish for social action, cultural shifts and political change" (Trugman, 2016: 1). Although beyond the scope of this investigation, fourth places are closely related to 'third places' in terms of social and behavioural characteristics, involving a radical departure from the routines of home and work, inclusivity and social comfort (Franck $\&$ Stevens, 2007). However, the activities, users, locations and spatial conditions that support them are very different. While in 'third places' conversation is the primary activity, in 'fourth places' it is all activities in-between the necessary activities: people-watching, walking, waiting, or killing-time. What distinguishes 'fourth places' the most are their location and character as well as their sense of publicness (e.g. broad spectrum of users; socially open; Aelbrecht, 2016).

\subsection{Geography of coffee shops, consumption spaces and retail landscapes}

The shift from Fordism to post-Fordism with its strong bearing on learning, creativity and innovation has led to the emergence of new socio-economic arrangements in cities. The new economic order depends on flexible, specialised and skilled urban labour as well as occupations requiring significant levels of human capital (Scott, 2014). Occupational categories and knowledge-intensive economic sectors such as managers, professional workers, business and financial analysts, scientific researchers, technicians, skilled crafts workers, designers and artists comprise the top tiers of the new economy (Scott, 2008; Kloosterman, 2010). People involved in the new economy have changed the retail landscape of cities and contributed to a renaissance of interest in urban culture. Certain types of restaurants, cafés, bars and shops have emerged in certain neighbourhoods as highly visible signs of gentrification (Zukin et al., 2009) and also as the "critical infrastructure of new urban culture" (Zukin \& Kosta, 2004: 102). Coffee shops typify urban regeneration (Bell, 2007) and the development of habitable and hospitable cities (Thrift, 2005). Murphy (2016) has correlated the prevalence of coffee shops with deprivation and crime, noting that more coffee shops in a certain precinct coincided with less crime - strongly suggestive of gentrification. Consumption spaces, such as coffee shops, have a powerful influence on attracting new residents while also leading to a subtle gentrification of inner city social spaces (Bell, 2007).

\subsection{Place attachment, interior and exterior attributes of coffee shops}

Consumers evaluate a design scape to understand a locale's place meaning or identity. By doing so, they are able to answer internal questions, such as "what is this place?" and "will I be able to fulfil my goals in this locale?" (Hall, 2008: 1). Another factor that influences human behaviour regarding choice of third places (coffee shops, wine bars, and craft beer boutiques) is place attachment. This involves the creation of positively experienced bonds over time from the behavioural, affective and cognitive ties between individuals and/or groups and their socio-physical environments (Brown \& Perkins, 1992; Waxman, 2006). Waxman (2006) has even made a comprehensive assessment, from an architect's point of view, of social spaces, especially coffee shops. According to Proshansky, Fabian and Kaminoff (1983) the experience of place is unique to each individual and is directly related to his or her lived experiences. Attachment to place comes about through a set of related phenomena rather than a singular phenomenon (Low \& Altman, 1992). In a study, exploring the characteristics that encourage gathering behaviour and contribute to place attachment in selected coffee shops Waxman (2006) found that the top five design considerations included cleanliness, appealing aroma, adequate lighting, comfortable furniture, and a view to the 
outside. Lukito and Xenia (2018) aver that contemporary cafés need to meet at least 'middleclass standards' for cleanliness and interior in order to brand themselves and compete with other cafés. The Viennese cafés set the standard when the exterior and interior of coffee consumption spaces are considered. Waiters wore tailcoats, and cafés featured marble tables, plush velvet couches, and elegant chandeliers (Hoeller, 2015). Modern cafés like Starbucks offers modern designscapes, free Wifi and sockets to charge smartphones and laptops as well as a comfortable seating for social interaction; a remarkable thing that Starbucks does besides marketing modern lifestyles and technology driven by globalization is local adjustment to particular places (Lukito \& Xenia, 2018).

\section{Research methodology}

A mixed-methods approach was followed to collect primary and secondary data and information. Primary data was collected by undertaking transect walks; and conducting a questionnaire survey among coffee drinkers in Stellenbosch. Moreover, in-depth interviews were held with the owners or managers of three speciality coffee shops and the activities and interactions of the coffee drinkers were observed at these selected consumption spaces. Data collection commenced with an exploratory walk through the historical part of Stellenbosch to grasp the sense of place of the precincts which host concentrations of coffee shops or ribbon developments along the main streets in the historical town centre. This orientation walk assisted the selection of three speciality coffee shops for in-depth case study. Transect walks were conducted street by street in the downtown area of Stellenbosch to capture physical and relative locations ${ }^{3}$ of coffee shops in a geographical information system (GIS). A questionnaire survey comprising 25 questions was conducted among Stellenbosch residents and coffee shop clientele to establish a demographic profile of the coffee consumers and their consumption patterns. Some of the questions required participants to rank the importance of the physical, social and environmental characteristics of coffee shops. Most of the questions were based on those posed in previous research on third places and attachment to places in coffee environments (Waxman, 2006; Tumanan \& Lansangan, 2012). In total 133 questionnaires were completed. Figure 1 (a), (b) and (c) provides the demographic profile of the respondents.

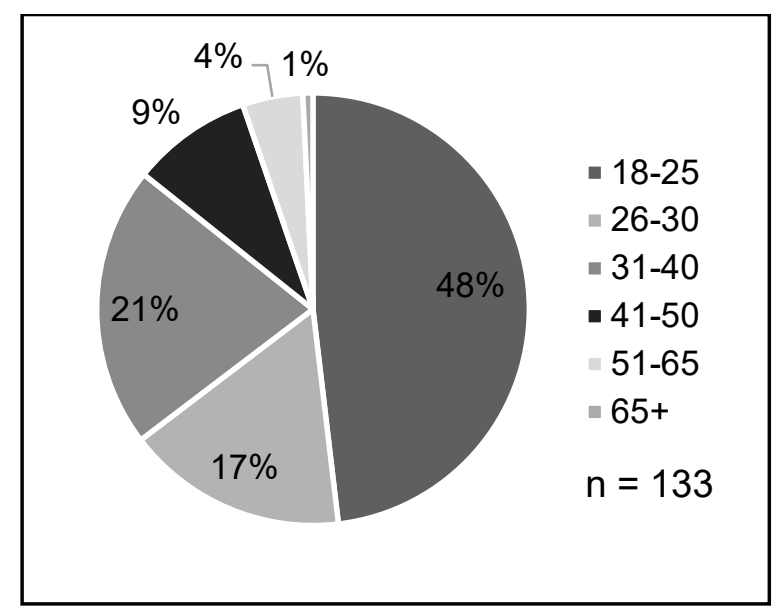

Figure 1a): Age of respondents

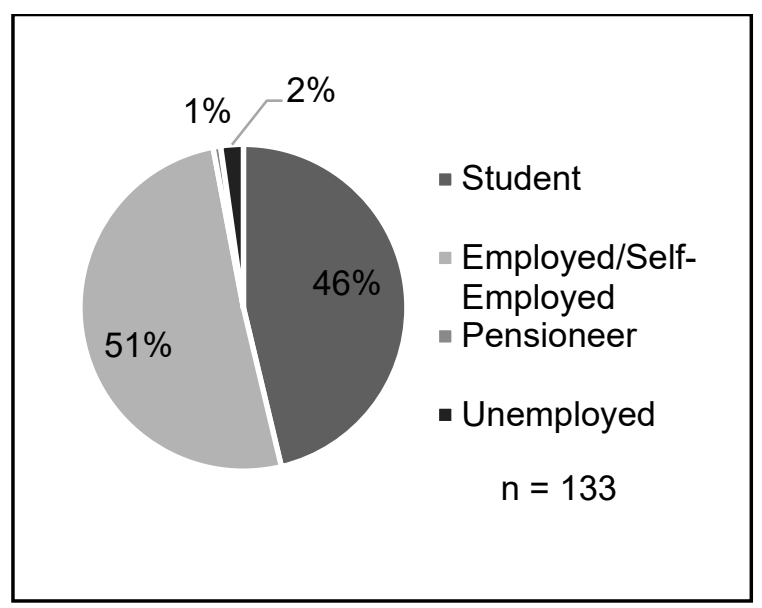

Figure 1b: Occupation of respondents

\footnotetext{
${ }^{3}$ This involved the coffee shops' location relative to other superstructures, such as historical buildings, educational facilities, tourist facilities, legal and financial offices.
} 


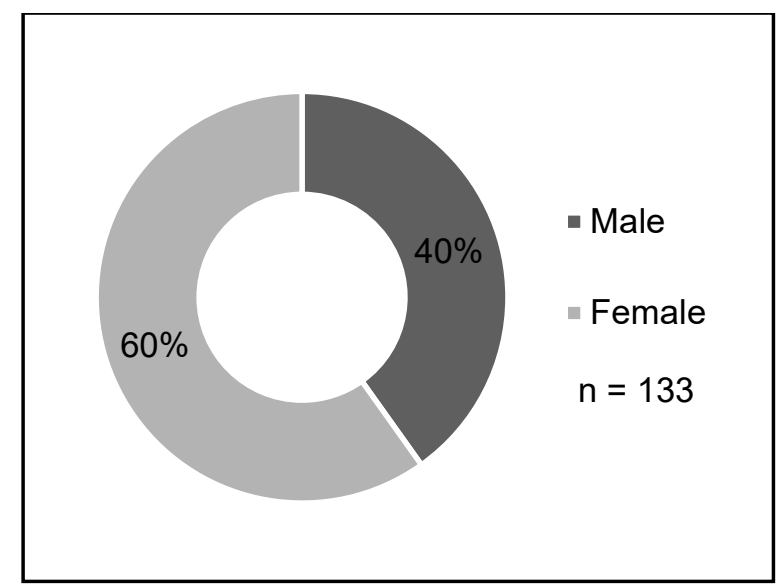

Figure 1c: Gender of respondents

Figure 1: Demographic structure of respondents (illustration: Lukas Beuster).

In each case study, notes were made about external and internal design features such as furniture, artificial and natural lighting, placement and availability of electrical socket outlets, views and the presence of music. Part of a visual documentation process was the photographing of the exterior and interior of each coffee shop. To capture the demographic profiles, the consumption and behavioural patterns of the customers of the three selected coffee shops, undisclosed participant observation was done. Patrons in each coffee shop were observed over at least a two-week period during different times of the day and week. After the data collection process was completed, all data and information gathered underwent qualitative and quantitative analyses. The quantitative analysis was completed using SPSSSoftware. Three qualitative information assisted in explaining the geography of preferred coffee shops, and how these social spaces contribute a hospitable town and vibrant café culture.

In the following subsection the study area is introduced as context for the investigation of the geography of coffee shops (third places); their location is examined; and results of the questionnaire survey on the social and physical factors which influence the preferences for certain coffee consumption spaces and the three speciality coffee shops are presented.

\section{The geography of coffee shops in Stellenbosch: A case study}

Stellenbosch - a university city - of about 160000 residents. It is a major tourism node in the Cape Winelands district (Ferreira \& Hunter, 2017). A substantial part of the town's population is made up of students of Stellenbosch University (32 000 in 2018) (Stellenbosch University 2018). Stellenbosch has an affluent business society and hosts the headquarters of a number of large corporations spanning the finance, agribusiness and health care sectors. 


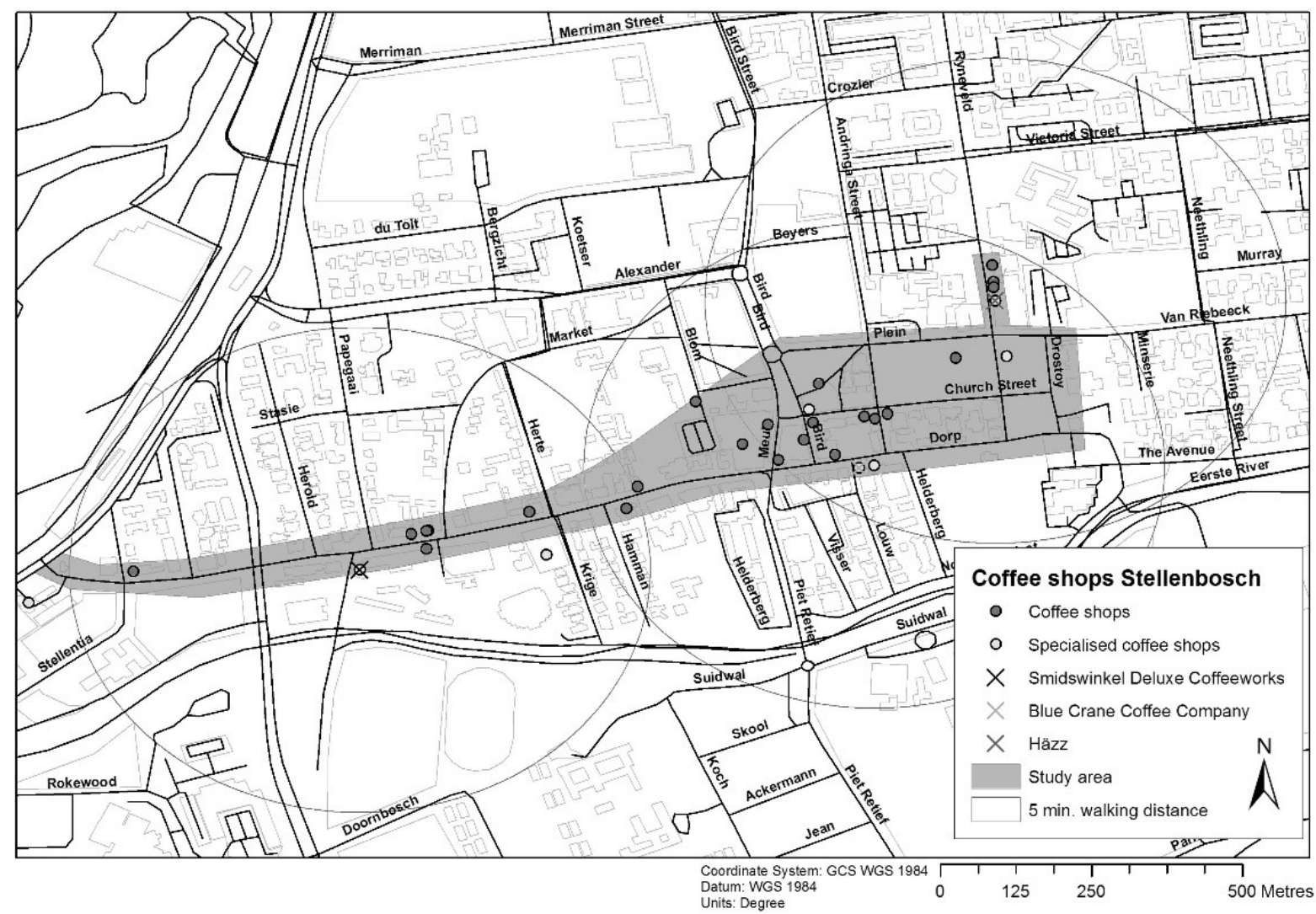

Figure 2: The distribution of coffee shops in central Stellenbosch (illustration: Lukas Beuster).

\subsection{Study area}

The study area (Figure 2) covers the historic downtown area of Stellenbosch, which is a popular walkthrough for tourists along streets lined with outdoor sculptures, galleries, eateries, coffee shops and souvenir shops. Church Street is the centre of the precinct where the 'cappuccino society meets', an area possessing a variety of consumption spaces amid an historic Cape Dutch townscape (Stellenbosch 360, 2018). Church Street is located in the corporate and social centre of town in close proximity of the university campus, many office buildings and retail shops. Another popular consumption space is along the lower part of Dorp Street with its ambience of Cape Dutch heritage and lined with a variety of eateries, bars and coffee shops with office-filled streets branching off it. This area is also close to residential buildings. These consumption spaces are ideally situated for entertaining tourists, students and office workers so that they are very popular and convenient destinations for an early-morning coffee, but especially over lunchtime and after work hours.

The findings of this study are presented following in three parts. First, the geography of the coffee shops is described. Second, the general consumer preferences for the coffee spaces in Stellenbosch are discussed. Third, insights gained from the case studies of the three speciality coffee shops are presented.

\subsection{Location of coffee shops in Stellenbosch}

The study area includes 22 coffee shops and nine speciality coffee shops (Figure 1). Some of these shops are part of national franchise networks and others are individually owned. The distribution pattern of the coffee shops reveals three clusters in the study area. The three case 
studies were purposively selected to ensure that one speciality coffee shop from each cluster was investigated. The Ryneveld Street-Van Riebeeck Street 'incipient cluster' is composed of six coffee shops, two of which are categorised as speciality coffee shops. One of the case studied speciality coffee shops, Häzz which belongs to a national coffee chain, is located in this cluster. These six shops are located within a five-minute walking zone from the southwestern end of the university campus, the surrounding residential area and the social hub (defined in the next paragraph) of the town. Ryneveld Street is one of the popular walkthroughs or corridor streets between the university campus and the centre of town. The coffee shops form part of a ribbon of social gathering spaces and retail shops. Students are the dominant clientele of these coffee shops and owing to the venues proximity to the centre of town, their other patrons originate from the nearby offices and retail buildings as well as visitors to Stellenbosch. During days parking opportunities in this area are extremely hard to find. The second cluster is in Church Street, the southern part of Bird Street and the central part of Dorp Street where it comprises eleven coffee shops, two of which are speciality shops. Blue Crane Coffee Company, a case study, occurs in this aggregation. This group of coffee shops is situated in the town centre - the old water wheel precinct ${ }^{4}$ - that constitutes the social hub of the city and main touristic area. Interspersed between these coffee shops are eateries, galleries and wine bars so that these consumption spaces are well frequented during the day, but especially just after work. The patrons of these coffee shops represent a diverse population due to the areas central location and accessibility by foot. Paid parking in this area is scarce but available. The lower Dorp Street aggregation - third incipient cluster - between Market Road and Herold Street comprises five coffee shops, two of which are specialty. Dorp Street, the main access road into the centre of town, is extremely busy with vehicle traffic during rush hours. This cluster is within a five-minute walking zone to a variety of corporate offices and apartment blocks so that it is highly frequented by the working population of Stellenbosch. It is more than five minutes walking distance from the town centre and even farther from the university campus, so limiting the number of student patrons during the day. However, this distance does not prevent them from flocking there 'en masse' during the early evenings. The case studied Smidswinkel Deluxe Coffeeworks is located in this area.

\subsection{Preferences of the coffee society of Stellenbosch}

This subsection furnishes an account of the responses given in the questionnaire survey regarding consumer preferences for coffee shops in Stellenbosch. The main reasons for visiting a coffee shop (in descending order of importance) are to drink coffee; to socialise; to work or study; to relax; and to eat. According to an assessment on a five point Likert-scale of the importance of the social and physical factors which influence preferences for certain coffee shops, were quality of the coffee (4.7), cleanliness (4.5), the quality of service (4.4), staff friendliness and expertise (4.3) and ambience (4.1) (Figure 3).

\footnotetext{
${ }^{4}$ The derelict historic waterwheel was reinstalled in April 2018.
} 


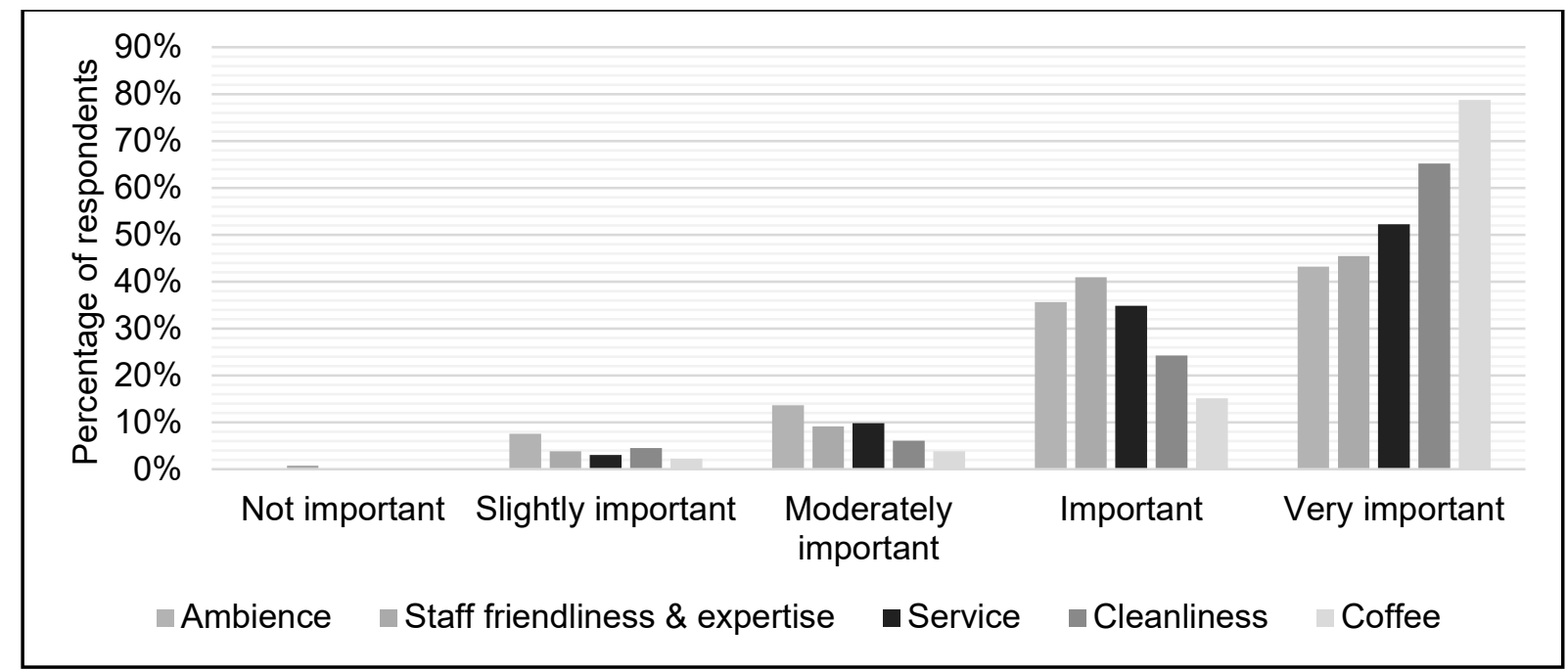

Figure 3: Factors influencing respondents' preferences for coffee shops in Stellenbosch (illustration: Lukas Beuster).

The survey also revealed differences between certain preferences of men and women. Women rated comfortable seating, exterior and interior design, menu options, Wi-Fi, safety and parking higher than men did. The greatest difference was for comfortable seating where the women respondents' average rating was 4.0 as opposed to that of men (3.5). Furthermore, differences were found between the preferences of students and the working population (Figure 4). The latter rated staff-visitor interaction, comfortable seating and availability of parking their most important factors, while for students the primary consideration were ambiance, comfortable seating and staff visitor interaction. A noteworthy difference between the two groups was their rating of parking availability. The working population's average rating for the importance of available parking is 3.5, while the students rating were 3.0. 


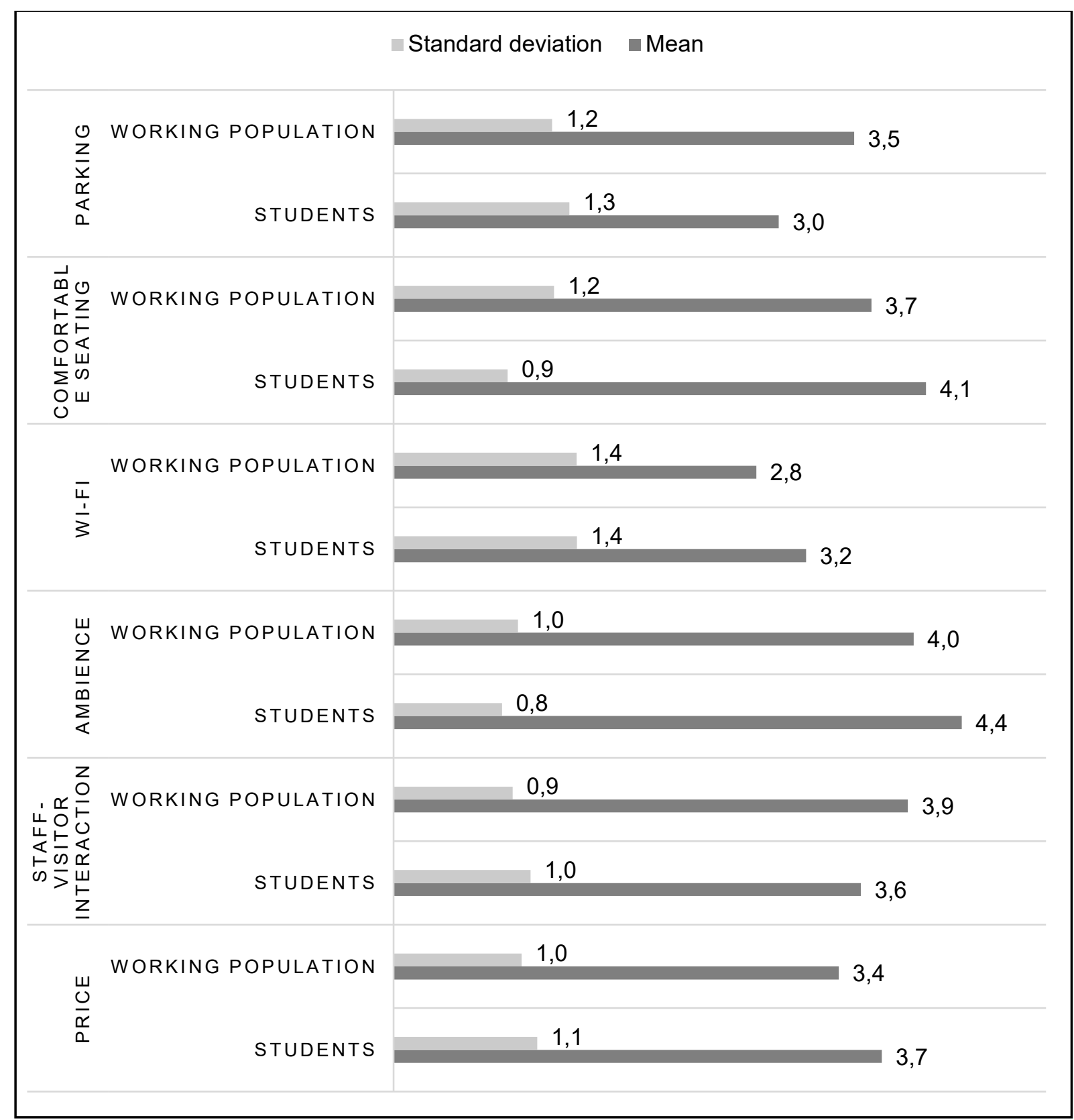

Figure 4: Working population versus university student's preferences on certain factors influencing their patronising of coffee shop (illustration: Lukas Beuster).

\section{Case Studies: Three speciality coffee shops}

The following section presents the insights from the three speciality coffee shops. The drawcards of the three selected coffee shops - Smidswinkel Deluxe Coffeeworks, Häzz and Blue Crane Coffee Company are good quality coffee, their relative locations, their individual exterior architectures, special interior ambiences and the availability of parking. The Smidswinkel Deluxe Coffeeworks case is a member of a regional specialty coffee shop chain with four shops in Cape Town and two in Stellenbosch. The case study speciality coffee shop was established in 2014, is privately owned and locally managed. It is located on the periphery of the study area, in easy walking distance from the Blitzbokke's ${ }^{5}$ accommodation

\footnotetext{
${ }^{5}$ Blitzbokke is the name of the South African national rugby sevens team.
} 
facility and training grounds as well as near to a concentration of professional services housed in adjacent office buildings, but relatively far from the university campus and the social hub of the town. The coffee shop is housed in an historic Cape Dutch building and is located at the corner of a three-way intersection on Dorp Street, the busy arterial street. There are no other coffee shops in its immediate vicinity. The exterior (Figure 5) features of the building gives no indication of the look and feel of the interior (Figure 6). There is ample parking nearby which is a considerable advantage in a parking deficient town. Regular consumers can park right in front of the shop for takeaway coffees or short visits.

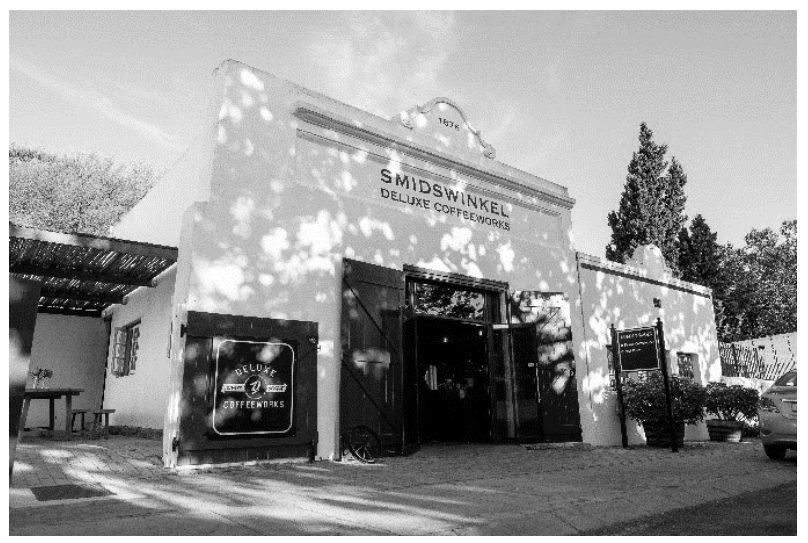

Figure 5: Exterior view Smidswinkel Deluxe Coffeeworks (photo: Lukas Beuster).

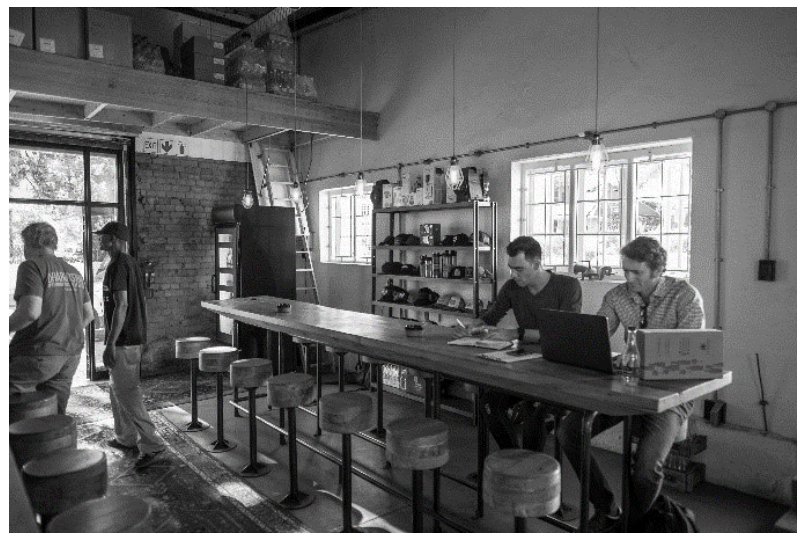

Figure 6: Interior view Smidswinkel Deluxe Coffeeworks (photo: Lukas Beuster).

According to the manager of Smidswinkel Deluxe Coffeeworks, the Shop's location was mainly chosen for the availability of parking and the proximity to legal, financial, an architects and agribusiness related office environments. The interior of Smidswinkel Deluxe Coffeeworks comprises a large service counter with a black tiled floor and ample seating. The seating arrangement features three large tables inside and four on the outside, the latter doubling the seating capacity. The tables are at both sitting and standing height with reasonably comfortable barstools and benches to create a casual seating arrangement. Most of the furniture is custom designed for this shop and features much exposed wood and painted steel to give an industrial but clean look (Figure 6). Background music is a mix but mostly rock music, which compliments the ambience, is audible inside the shop but fades outside. The shop is designed for quality-conscious customers. Service quality, customer interaction and the creation of a friendly atmosphere are managements' most important considerations along with the promotion of a certain lifestyle and the offering of high-quality coffees, juices, alcoholic beverages and snacks. The targeted consumer group is not age specific, rather personality related (Wijnbeek, 2017, pers.com). Personal observation revealed that members of the new economy working population of Stellenbosch primarily frequent the shop during 
their free time, scheduled meetings or to socialise and relax after work. The coffee shop invites a lingering behaviour and more patrons consume their coffee in-house than as takeaways or coffee on the go. The size of the tables enables people to share the space without sacrificing individual privacy while facilitating interaction between visitors. Few students frequent the shop during the morning, but their numbers increase during the afternoons. In the afternoons, the shop is frequented by a variety of people from different age groups who socialise, work, study or relax with a drink. Most of the clients appear to be regulars. No visible menu is available and the customers engage actively with the staff so increasing staff visitor interaction. Service is generally quick with queues only forming during rush hours and they usually remain short.

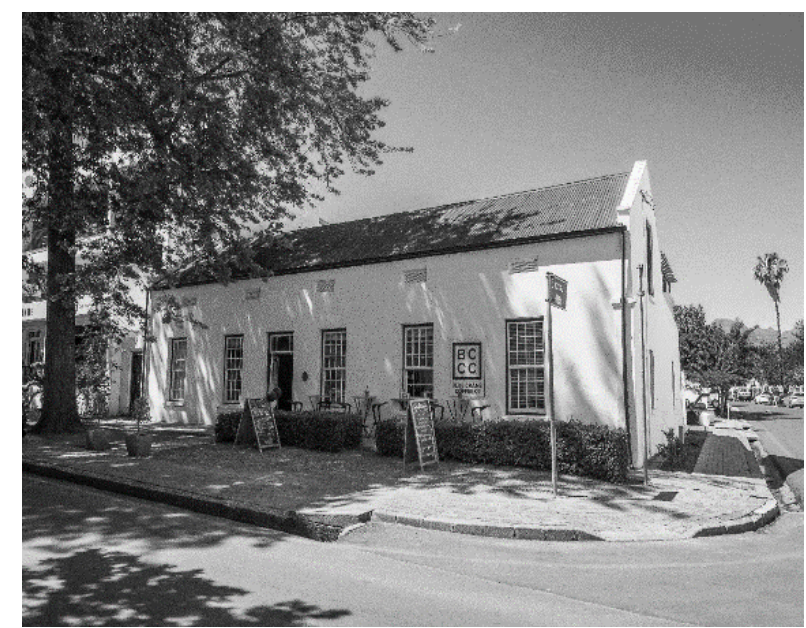

Figure 7: Exterior view Blue Crane Coffee Company coffee shop (photo: Lukas Beuster).

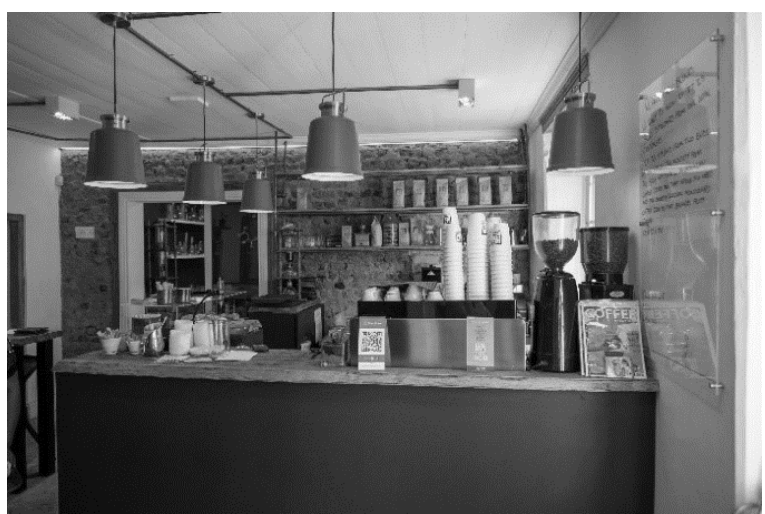

Figure 8: Interior view Blue Crane Coffee Company coffee shop (photo: Lukas Beuster).

The Blue Crane Coffee Company is a speciality coffee shop and part of a local coffee shop brand. ${ }^{6}$ The shop is privately owned, locally managed and opened at the beginning of 2017. It is located on a busy arterial route lined with various restaurants, cafés, offices and shops. It is located on the outer edge of the social hub of the town as part of a ribbon of retail shops, offices and eateries in upper Dorp Street (recall Figure 2). The coffee shop is housed inside of an historic Cape Dutch building and necessarily has little branding or advertising on the exterior of the building (Figure 7). The owners previously used the building as office space, the venue was chosen owing to its availability and proximity to the family's other business. It is the first of their shops to focus on the coffee experience by serving as a roaster and as a

\footnotetext{
${ }^{6}$ There are two Blue Crane Coffee shops in Stellenbosch - both family owned - only one of them is case studied.
} 
coffee shop with a small point of sale, a dedicated takeaway window and limited seating capacity (Joubert, 2017). The Blue Crane Coffee Company has the smallest physical space of the three case studied coffee shops. The main room features four wooden tables at standing height with barstools for seating. There is also a lounge with a sofa and armchairs. Because space is at a premium, the tables in the main room are quite narrow and there is little space between the reasonably comfortable stools and the tables. Glass doors are fitted as partitions between the rooms to create an illusion of space in a small area. The coffee shops' interior is an open design and the visitors can see the roasting machine and the coffee laboratory through glass doors. Its minimalist interior design, in conjunction with the exposed wood creates a warm and peaceful atmosphere, amplified by subtle background music, which is changed regularly (Figure 8).

Due to the limited availability of space in the shop, it was purposely designed to appeal to quality-conscious customers for quick takeaways and short coffee breaks throughout the day. Given the shop's location in close proximity to offices, the target customers are high-end professionals, specifically from the investment, legal, auditing and private banking sectors. The shop is managed with an emphasis on excellent quality coffee, a professional mind-set and personalised service to the extent that staff memorise regular customers tastes and preferences so that they do not need to vocalise their orders (Joubert, 2017). Due to the shop's location on the edge of the social hub, the professionals or the so-called creative class of Stellenbosch frequent it daily. Observations confirmed other consumers too - university students and tourists. The shop's main business is take away coffees and these customers do not linger. The limited space inside attracts people who want to work and ample socket outlets allow for long work sessions. The lounge is a veritable social space used by small groups for relaxing and socialising.

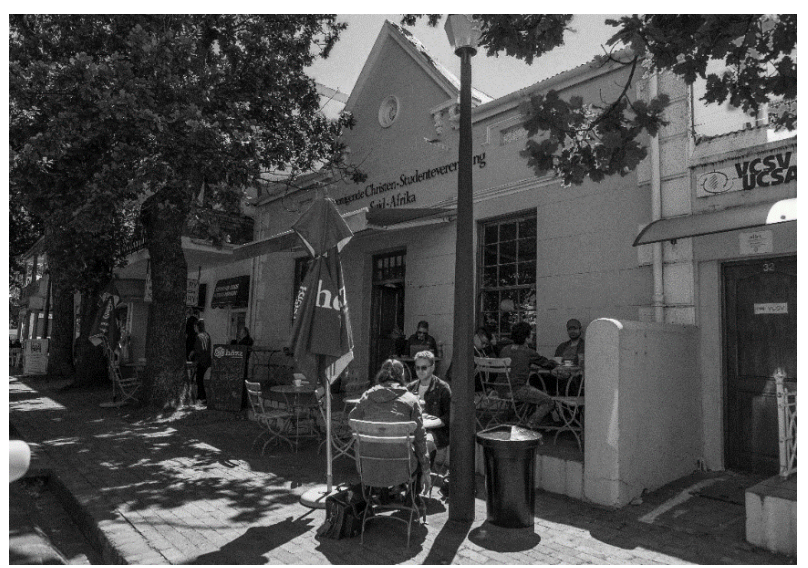

Figure 9: Exterior view of the Häzz coffee shop (photo: Lukas Beuster).

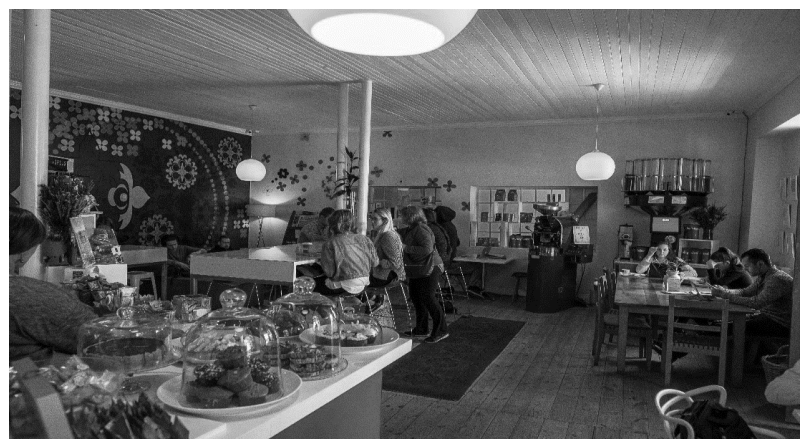

Figure 10: Interior view of the Häzz coffee shop (photo: Lukas Beuster). 
Häzz is a specialised coffee shop and part of a regional chain that is privately owned and locally managed. The shop opened in 2009 and has changed owners since then. It is the longest established of the three case studies and is located on the periphery of the social hub of town but in close proximity to the university campus. It is located with other coffee shops, galleries and retail stores along the main walkway from campus to town. Although it is located near a large paid-parking lot, the acute shortage of parking near the university campus and the town centre, customers must park at some distance and walk to the shop. The shop's exterior is plain and there are tables on the sidewalk in front of the shop so increasing visibility (Figure 9). On busy days, there is a dedicated takeaway station outside the coffee shop, so reducing the number of people queueing inside for sit-down service. The interior is fitted with a large service counter and nine tables, two high-standing tables, one coffee table with an adjacent sofa, one large conference table and five tables of normal height (Figure 10). Additionally, most of the tables are equipped with socket outlets for recharging devices during long work sessions. The whole shop feels a little outdated. The location was chosen to be close to the university campus and the interior was purposefully designed to appeal to female students. A new, smoother and lighter coffee blend of high quality was created to satisfy especially the palettes of women coffee drinkers. The availability of ample sweets, snacks and lunch options is intended to attract students. It interior was designed to cater for a large number of people and to allow for a wide range of customers by purposely creating variety and different levels of tables to enlarge the perceived space so enabling individuals and groups of different sizes to find appropriate spots to sit (Freeman, 2017). The proximity to campus is clearly reflected in the demographics of customers in the shop, namely mostly the young female students. Although located away from the social hub of the town as opposed to Blue Crane Coffee Company's location, Häzz is well situated to cater for the working population and tourists. Häzz is nearly always crowded and it is rare to find a place to sit inside during busy hours and after lunch so that many customers take their coffees to go. Despite the shop being very noisy during peak times, many patrons spend their time working and socialising with friends. Service is relatively slow and often-long queues result from the great number of customers who arrive at once during class break times at university.

\section{Discussion and conclusion}

The three speciality coffee shops share certain characteristics that are attributable to an attachment to a preference for a specific place (relative location, historical buildings; Zukin, 1987). All three shops serve high-quality coffee, are attractive spaces and are well maintained, each one an important factor influencing consumer preferences for a coffee shop regardless of gender or current occupation. All three coffee shops have free access to Wifi, provide a safe environment and have plain and unobtrusive exteriors. The latter feature attests to local building regulations regarding the preservation of the look and feel of the historical core. Although, the interiors of the three shops are unalike for, attracting particular kinds of clientele all three provide a hospitable ambiences. Opposed to these similarities, the shops have their individual foci and features that influence coffee lovers' choices and preferences (Hall, 2008). Smidswinkel Deluxe Coffeeworks concentrates on service quality, friendly staff and staff visitor interaction, all of which are favoured by the professional working population. Blue Crane Coffee Company pays attention on service quality and friendly staff, both being preferred factors by professionals who are their main target market (Laurier and Philo, 2007). Although, this coffee shop has an appealing interior design, which the survey found to be more attractive to women, its relative location near to the office-buildings housing professional services appears to attract mainly male customers. Häzz gives prominence to 
comfortable seating and provides a variety of competitively-priced menu options, including lunch and snacks, which are important attractions for students and women, the shops' main target groups.

The primary factor found to influence most respondents' preference for certain coffee shops was a shop's convenient location in easy walking distance from places of study or work. This attribute is clearly observable in the customer base in each shop: students comprise the majority at Häzz close to the campus, a considerable quota at Blue Crane Coffee Company and only a minority at Smidswinkel Deluxe Coffeeworks during the regular hours of the day. Similarly, for the working population proximity is the common denominator in coffee shop preference. Smidswinkel Deluxe Coffeeworks is near offices whose occupants use the shop for coffee breaks, meetings and socialising. The coffee shops in Stellenbosch are illuminating examples of how locations catering for different target markets because preferences cannot be equally distributed among various locational choices (Turhan et al., 2013). Both Blue Crane Coffee Company and Smidswinkel Deluxe Coffeeworks are located primarily in highturnover environments and secondarily in spaces for longer lingering. Häzz, while having to adhere to a high-turnover strategy, must also offer optional extras to students looking for a hospitable and convenient venue to work in.

The coffee shops in Stellenbosch are third places which people frequent for a variety of activities like drinking coffee, working (away from formal office environments), having meetings, socialising and relaxing (Oldenburg, 1999). Stellenbosch's coffee shops offer the convenience of a quick break from the office and much needed social interaction. This interaction mainly happens in existing social groups, the coffee shop being a fitting meeting point. Moreover, the coffee shops are also platforms for establishing new connections among regulars. This was specifically observed at Blue Crane Coffee Company where regulars have begun to form bonds while socialising in the congenial environment of the shop. The town's coffee shops are also venues for transacting business, conducting meetings and displaying one is being part of a community. The coffee shops have become an integral part of both the working and professional culture as well as student culture in Stellenbosch, with members of these groups visiting the coffee shops almost daily. In the town's vibrant centre - the Church Street precinct - the choice of commercial space is extremely limited. The three selected coffee shops were originally located in available commercial space as close as possible to their respective target markets (Freeman, 2017; Joubert, 2017; Wijnbeek, 2017) as an extra bonus gave the three historical buildings - who house them - new functions and thus longer shelf-lives.

Given the growth in the knowledge-based industries, the presence of professional services and affluent student and resident communities Stellenbosch shows all the signs of a thriving town or a secondary city ${ }^{7}$. The café culture is evident in the coffee shops, bistros, restaurants and wine bars so that Stellenbosch's town centre has developed into a 'gastro-tourism' precinct or a commercial hospitality hub as coined by Bell (2007). These consumption spaces, which include coffee shops, have played a role in the gentrification of these areas where crime is reported to be lower in relation to other areas in the town centre. The interviewed managers of the case studied coffee shops contend that the coffee market is showing early signs of saturation. This poses questions about the viability of certain coffee shops and raises the issue of the wise placement of new entrants. A lack of retail space, competition from other social gathering spaces and very high rentals will inevitably curtail

\footnotetext{
${ }^{7}$ According to Marais, Nell and Donaldson (2016) is Stellenbosch a secondary city.
} 
the establishment of more coffee shops. The issuing of licences by the local municipality can turn a good location for a coffee shop into an undesirable and unprofitable one. Through the ages, people have altered their surroundings in various ways to better suit their perceived needs. Through this process, we become focused on change and the evolution of our built environment, discarding outdated spaces or converting them in new functional spaces, places where society can form new bonds that can contribute to cohesion in urban societies.

Sanette Ferreira, Department of Geography and Environmental Studies, Stellenbosch University, South Africa (slaf@sun.ac.za)

Lukas Beuster, Department of Geography and Environmental Studies, Stellenbosch University, South Africa (21376042@sun.ac.za)

\section{Acknowledgements}

Special acknowledgements are extended to referees on earlier versions of this paper. The usual disclaimers apply.

\section{References}

Aelbrecht, P. S. (2016) 'Fourth places': the contemporary public settings for informal social interaction among strangers. Journal of Urban Design, 21(1), pp. 124-152. DOI: 10.1080/13574809.2015.1106920

Austin, P. M. \& Whitehead, D. C. (1998) Auckland: Cappuccino city?. Urban Policy and Research, 16(3), pp. 233-240. DOI: 10.1080/08111149808727770

Baskerville, P. (2015) What's the secret to a successful coffee shop. Available at: https://www.quora.com/Whats-the-secret-to-a-successful-coffee-shop (accessed 21 May 2018).

Bell, D. (2007) The hospitable city: Social relations in commercial spaces. Progress in Human Geography, 31(1), pp. 7-22. DOI: 10.1177/0309132507073526

Brown, B. \& Perkins, D. (1992) Disruptions in place attachment. In: Altman, I. \& Low, S. (eds.) Place attachment, pp. 279-304. New York, Plenum Press. DOI: 10.1007/978-1-4684-8753-4_13

Cowan, B. (2005) The social life of coffee - The emergence of the British coffeehouse. New Haven, Yale University Press.

Elliott, C. (2001) Consuming caffeine: The discourse of Starbucks and coffee. Consumption Markets \& Culture, 4(4), pp. 369-382. DOI: 10.1080/10253866.2001.9670363

Ferreira, S. L. A. \& Hunter, C. A. (2017) Wine tourism development in South Africa: A geographical analysis. Tourism Geographies, 19(5), pp. 676-698. DOI: 10.1080/14616688.2017.1298152

Freeman, P. J. (2017) Original owner of Hazz coffee shop, Stellenbosch (interview, 19 Oct. 2017).

Franck, K. A. \& Stevens, Q. (2007) Loose space: Possibility and diversity in urban life. London, Routledge.

Habermas, J. (1989) The structural transformation of the public sphere: An inquiry into a category of bourgeois society. Cambridge, Polity Press.

Hall, C. M. (2008) Servicescapes, designscapes, branding, and the creation of place-identity: south of Litchfield, Christchurch. Journal of Travel \& Tourism Marketing, 25(3), pp. 233-250. DOI: $10.1080 / 10548400802508101$

Hoeller, S. (2015) Here's why coffee is such an important part of the culture in Vienna. Available at: $\mathrm{http}: / / w w w . b u s i n e s s i n s i d e r . c o m / c o f f e e-c u l t u r e-i n-v i e n n a-h i s t o r y-2015-10$ ? ir=t (accessed 13 July 2018).

Hyra, D. (2017) Race, class, and politics in the Cappuccino City. Chicago, The University of Chicago Press. DOI: $10.7208 /$ chicago/9780226449678.001.0001

Joubert, C. N. (2017) Operations manager, Blue Crane Coffee Company, Stellenbosch (interview, 19 Oct. 2017).

Kafadar, C. (2014) A history of coffee. Available at: https://sites.duke.edu/ rethinkingglobalcities /files/2014/09/64Kafadar16-offeehistory.pdf (accessed 13 June 2018).

Kjeldgaard, D. \& Ostberg, J. (2007) Coffee grounds and the global cup: Glocal consumer culture in Scandinavia. Consumption Markets \& Culture. 10(2), pp. 175-187. DOI: 10.1080/10253860701256281

Kloosterman, R. C. (2010) This is not America: Embedding the cognitive-cultural urban economy. Geografiska 
Annaler, Series B, Human Geography, 92, pp. 131-143. DOI: 10.1111/j.1468-0467.2010.00338.x

Landry, L. \& Bianchini, F. (1995) The creative cCity. London, Demos.

Laurier, E. \& Philo, C. (2005) The cappuccino community: Cafés and civic life in the contemporary city (draft). Glasgow, University of Glasgow, Department of Geography and Topographic Science.

DOI: $10.1080 / 14649360701360212$

Laurier, E. \& Philo, C. (2007) A parcel of muddling muckworms: Revisiting Habernmas and English coffeehouses. Social \& Cultural Geography, 8(2), pp. 259-281.

Lillywhite, B. (1963) London coffee houses. London, George Allen and Unwin Ltd.

Lovatt, A. \& O'Connor, J. (1995) Cities and the night-time economy. Planning Practice and Research, 10, pp. 127-133. DOI: 10.1080/02697459550036676

Low, S. M. \& Altman, I. (1992) Place Attachment. In: Altman, I. \& Low, S.M. (eds.) Place Attachment, pp. 112. Boston, Springer. DOI: 10.1007/978-1-4684-8753-4_1

Lukito, Y. N. \& Xenia, A. P. (2018) Experiencing contemporary cafés and changes in the characteristic of third places. IOP Conference. Series. Earth Environmental. Science, 126, pp. 1-12. Available at: http://iopscience.iop.org/issue/1755-1315/126/1.pdf (accessed 19 June 2018).

Marais, L., Nell, E. \& Donaldson, R. (2016) Secondary cities and development. London, Routledge. DOI: $10.4324 / 9781315667683$

Montgomery, J. (1997) Cafe culture and the city: The role of pavement cafes in urban public social life. Journal of Urban Design, 2(1), pp. 83-102. DOI: 10.1080/13574809708724397

Murphy, D. (2016) Crime stats or coffee shops? How to spot the world's most gentrified cities. Available at: https://www.theguardian.com/cities/2016/sep/30/worlds-most-gentrified-cities-crime-stats-coffee-shops (accessed 17 May 2018)

Oldenburg, R. (1999) The great good place. New York: Marlowe \& Company.

Oosterman, J. (1992) Culture and Urban Regeneration: Some European Examples. Built Environment, 18(2), pp. $155-164$.

Örs, I. (2002) Coffeehouses, cosmopolitanism, and pluralizing modernities in Istanbul. Journal of Mediterranean Studies, 12(1) pp. 119-145.

Papachristos, A. V., Smith, C. M., Schererer, M. L. \& Fugiero, M. A. (2011) More Coffee, Less Crime? The Relationship between Gentrification and Neighbourhood Crime Rates in Chicago, 1991 to 2005. City \& Community,10(3), pp. 215-241. DOI: 10.1111/j.1540-6040.2011.01371.x

Pendergrast, M. (1999) Uncommon grounds: The history of coffee and how it transformed our world. New York, Basic Books.

Pincus, S. (1995) Coffee politicians does create: Coffeehouses and restoration political culture. Journal of Modem History, 67(4), pp. 807-834. DOI: 10.1086/245229

Proshansky, H. M., Fabian, A. K. \& Kaminoff, R. (1983) Place-identity: physical world socialization of the self. Journal of Environmental Psychology, 3(1), pp. 5783. DOI: 10.1016/S0272-4944(83)80021-8

Scott, A. J. (2008) Social economy of the metropolis. Oxford, Oxford University. DOI: 10.1093/acprof:oso/9780199549306.001.0001

Scott, A. J. (2014) Beyond the creative city: Cognitive-cultural capitalism and the new urbanism. Regional Studies, 48, pp. 565-578. DOI: 10.1080/00343404.2014.891010

Sennett, R. (1974) The Fall of Public Man. Cambridge, Cambridge University Press.

Shea, J. (2018) Vienna named best city to live in for ninth year running. Available at: https://www.independent.co.uk/travel/news-and-advice/vienna-best-place-live-quality-life-mercersurvey-sarajevo-a8262976.html (accessed 14 June 2018)

Sohrabi, N. M (2016) Coffee shop (Café), Public sphere for further reflections on social movements. Available at: http://sites.uci.edu/tehranproject/files/2016/02/coffeshop-tehran-project-2-edit.pdf (accessed 13 June 2018)

Stellenbosch 360 (2018) Stellenbosch-Inspiration-Imphembelelo-Inspirasie. Available at: http://www.stellenbosch.travel/attractions/caf\%C3\%A9-culture (accessed 18 June 2018)

Stellenbosch University (2018) Stellenbosch University annual integrated report 2018. Stellenbosch.

Thrift, N. (2005) But malice aforethought: Cities and the natural history of hatred. Transactions of the Institute of British Geographers, NS 30, pp. 133-50. DOI: 10.1111/j.1475-5661.2005.00157.x

Tjora, A. (2013) Café society. New York, Palgrave Macmillan. DOI: 10.1057/9781137275936

Topik, S. (2009) Coffee as a social drug. Cultural Critique, 71, pp. 81-106. DOI: 10.1353/cul.0.0027

Trugman, C. W. (2016) Community: Café culture and the relevance of a traditional third place in the social media era. Master's thesis, College of Arts and Sciences, Georgia State University.

Tucker, C. M. (2017) Coffee culture: Local experiences, global connextions. New York, Routledge. DOI: $10.4324 / 9781315678795$

Tumanan, M. A. R. \& Lansangan, J. R. G. (2012) More than just a cuppa coffee: A multi-dimensional 
approach towards analyzing the factors that define place attachment. International Journal of Hospitality Management, 31(2), pp. 529-534. DOI: 10.1016/j.ijhm.2011.07.012

Turhan, G., Akalın, M. \& Zehir, C. (2013) Literature review on selection criteria of store location based on performance measures. Procedia - Social and Behavioral Sciences, 99, pp. 391-402. DOI: $10.1016 /$ j.sbspro.2013.10.507

Waxman, L. (2006) The coffee shop: Social and physical factors influencing place attachment. Journal of Interior Design, 31(3), pp. 35-53. DOI: 10.1111/j.1939-1668.2006.tb00530.x

West, P. (2010) Making the market: Speciallity coffee, generational pitches and Papua New Guinea. Antipode, 42(3), pp. 690-718. DOI: 10.1111/j.1467-8330.2010.00769.x

Wijnbeek, M. (2017). Area manager Winelands, Smidswinkel Deluxe Coffeeworks, Stellenbosch (interview, 18 Oct. 2017).

Zukin, S. (1987) Gentrification culture and capital in the urban core. American Review of Sociology, 13, pp. 129-147. DOI: 10.1146/annurev.so.13.080187.001021

Zukin, S. \& Kosta, E. (2004) Bourdieu off-broadway: Managing distinction on a shopping block in the east village. City \& Community, 3(2), pp. 101-114. DOI: 10.1111/j.1535-6841.2004.00071.x

Zukin, S., Trujillo, V., Frase, P., Jackson, D., Recuber, T. \& Walker, A. (2009) New retail capital and neighborhood change: Boutiques and gentrification in New York City. City Community, 8(1), pp. 1-19. DOI: $10.1111 /$ j.1540-6040.2009.01269.x 